\title{
BMJ Open Beyond height and weight: \\ a programme of school nurse \\ assessed skinfold measurements from \\ white British and South Asian origin children aged 4-5 years within the Born in Bradford cohort study
}

\author{
Jane West, ${ }^{1,2}$ Gillian Santorelli, ${ }^{3}$ Laura Lennon, ${ }^{4}$ Kathy O'Connell, ${ }^{4}$ John Corkett, ${ }^{1}$ \\ John Wright, ${ }^{1}$ Shirley Brierley, ${ }^{4}$ Peter Whincup, ${ }^{5}$ Noel Cameron, ${ }^{6}$ \\ Debbie A Lawlor ${ }^{2,7}$
}

To cite: West J, Santorelli G, Lennon L, et al. Beyond height and weight: a programme of school nurse assessed skinfold measurements from white British and South Asian origin children aged $4-5$ years within the Born in Bradford cohort study. BMJ Open 2015;5:e008630. doi:10.1136/bmjopen-2015008630

\section{- Prepublication history} and additional material is available. To view please visit the journal (http://dx.doi.org/ 10.1136/bmjopen-2015008630).

Received 29 April 2015 Revised 22 September 2015 Accepted 9 October 2015

CrossMark

For numbered affiliations see end of article.

Correspondence to Dr Jane West; jane.west@bthft.nhs.uk

\section{ABSTRACT}

Objective: To describe the feasibility, reliability and additional information gained from collecting additional body fatness measures (beyond height and weight) from UK reception year children.

Design: Prospective cohort study.

Setting: Bradford, UK.

Participants: 2458 reception year children participating in the Born in Bradford (BiB) cohort study. Main outcome measures: The feasibility and reliability of subscapular and triceps skinfold measurements and differences in adiposity between ethnic groups.

Results: Of those children who were matched to their school, $91 \%$ had a subscapular skinfold measurement and $92 \%$ had a triceps skinfold measurement recorded. Reliability was generally over $90 \%$ for all measurers and both measurements. Pakistani children were slightly taller but weighed less and had lower triceps skinfold thickness (mean difference $-1.8 \mathrm{~mm}$, $95 \% \mathrm{Cl}-2.1$ to $-1.4 \mathrm{~mm}$ ) but higher subscapular (mean difference $0.1 \mathrm{~mm}, 95 \% \mathrm{Cl}-0.1$ to $0.4 \mathrm{~mm}$ ) than white British children.

Conclusions: We have shown that it is feasible for school nurses to collect skinfold measurements in a similar way to the height and weight measurements collected from reception year children for the National Child Measurement Programme (NCMP), and that these measurements are reliable. It is important for healthcare practice to acknowledge ethnic-specific risk and these additional measurements can provide important information to examine population-level risk in populations with large proportions of South Asian children.

\section{BACKGROUND}

Childhood obesity is likely to play an important role in future cardiometabolic health ${ }^{1}$

\section{Strengths and limitations of this study}

- A key strength of this study is that we report for the first time, a city-wide programme of child skinfold thickness measurements by school nurse teams that compliment routine height and weight measurements to estimate fatness in reception age children.

- These teams successfully achieved coverage similar to that reported for the National Child Measurement Programme (NCMP) and our results suggest that these measurements are reliable.

- A potential limitation is that we were unable to match $33 \%$ of study children to their primary school, but we anticipate that for school years beyond reception, linkage of at least $85 \%$ of Born in Bradford (BiB) children to their school will be achieved.

and its prevention is now a global public health priority. ${ }^{2}$ Despite recent reports that rates of childhood obesity are stabilising, ${ }^{3}$ overall prevalence remains high ranging from a fifth to a third of young children in the USA and UK now overweight or obese. ${ }^{45}$ Concerns about childhood obesity have resulted in national or regional surveillance programmes that record weight and height in order to monitor trends in overweight and obesity based on body mass index (BMI), for example, the National Health and Nutrition Examination Survey (NHANES) in the USA and the National Child Measurement Programme (NCMP) in England. While BMI in childhood and adolescence is robustly associated with markers of cardiometabolic 
health and future incidence of type 2 diabetes and cardiovascular disease in adults, ${ }^{6-8}$ it may not be able to identify ethnic differences in either the levels or distribution of adiposity and hence distinguish risk between different ethnic groups at a population level. There is increasing evidence that for an equivalent BMI, South Asian children have greater total and central adiposity than white British children ${ }^{9}{ }^{10}$ and are potentially more metabolically sensitive to body fat. ${ }^{11}$ Our own work using the Born in Bradford (BiB) cohort (used in this publication $)^{12-14}$ and that of others, ${ }^{15-18}$ suggests that even at birth South Asian infants might have greater levels of fat for a given birth weight than white Europeans. Thus, public health surveillance that monitors overweight and obesity levels in children based on BMI might not accurately reflect future health burden. One solution might be to lower BMI thresholds for defining overweight and obesity in South Asian children; however, lowering such thresholds in South Asian adults does not seem to better predict future risk ${ }^{19} 20$ and therefore is unlikely to do so in children. An alternative would be to add additional measurements of body fat and distribution that might be able to provide a better idea of population-level risk in populations with large proportions of South Asian children.

Our aim in this paper is to examine the feasibility of adding reliable measurements of subscapular and triceps skinfold thickness to the UK NCMP in one city with a large proportion of South Asian children. We have chosen subscapular and triceps skinfolds because these do not require expensive and difficult to transport equipment, do not require children to show their waist, which some may find embarrassing or invasive in the school setting, and because these measures have been shown to accurately reflect peripheral and central adiposity levels. ${ }^{1521}$ Furthermore, other studies that include skinfold measurements obtained by research staff show that they are better discriminators of ethnic differences than is BMI. ${ }^{92}$

Specific objectives were (1) to examining the feasibility of school nurse teams undertaking skinfold thickness measurements from reception age children (4-5 years), as determined by the proportions of children in the cohort and by ethnicity and age who have valid skinfold measurements and how these compare to proportions with valid weight and height measurements, (2) to examine inter-rater reliability by comparing measurements undertaken on the same child between each nurse and a trained researcher in a subgroup of participants and (3) to compare BMI and the additional information gained from skinfold measurements between ethnic groups.

\section{METHODS}

Participants

This study was nested in the $\mathrm{BiB}$ cohort which is a prospective pregnancy and birth cohort based in the sixth largest city in the UK: Bradford in the North of England. The study was established to examine how genetic, nutritional, environmental, behavioural and social factors impact on health and development during childhood, and subsequently adult life, in a deprived multiethnic population. The study recruited women during pregnancy and has followed them, their partners and their infants through childhood. To be eligible for the study women had to attend antenatal booking clinic between March 2007 and December 2010 and be booked to give birth in the city of Bradford. Full details of the study methodology have been previously reported. ${ }^{23} \mathrm{~A}$ total of 12453 women who gave birth to 13818 liveborn children were recruited to the study. Of these 13818 children, 3730 were eligible to start school in the academic year 2012/2013 and these 3730 children form the sample for this study. Parents of eligible children were mailed information about the skinfold measurements 8 weeks prior to the scheduled measurements with an 'opt out' consent form and prepaid envelope should they wish to withdraw their child from the measurements. The opt-out consent is consistent with the consent process used for the NCMP and was approved by the National Health Service research ethics committee. Parental consent was refused for 77 (2\%) of children with similar proportions in the two main ethnic groups (white British $36(47 \%)$ and South Asian $41(53 \%)$ ) and of the 3653 for whom consent was not declined 1195 (33\%) could not be matched to their school, again this did not vary markedly by ethnicity (538 (45\%) were of South Asian origin and $657(55 \%)$ white British). The remaining 2458 form the sample for this study. Ethics approval for the study was granted by Bradford National Health Service Research Ethics Committee (ref 06/Q1202/48).

\section{Assessment of ethnicity}

Ethnicity was self-reported at the mother's questionnaire interview and based on UK Office of National Statistics guidance details of which have been previously reported. ${ }^{14}$ For the purpose of this study, the children are defined as white British; other white; Pakistani; other South Asian; other ethnicity.

\section{Linkage of BiB participants to primary schools}

The linkage to education data was done using a deterministic match based on the first name, last name, gender, date of birth and postcode. The rule for the matching was that there has to be a single definite match on each of these attributes in the Local Education Authority (LEA) database for them to provide us with the unique pupil number (UPN). Once we had the UPN we could download data about the children, including their school from the LEA website portal and verify for ourselves that the matches were accurate.

\section{The Bradford school nursing service}

The school nursing service in Bradford includes 110 nurses, nursery nurses and healthcare support workers 
working across 11 teams and covering 143 primary schools in Bradford. Each school has a named school nurse which ensures an integrated service where the school nurse and team are accessible and well known to the education staff, parents and children within each school. This relationship has supported a high response for the NCMP with $88-91 \%$ of reception age children in the city having valid height and weight measurements over the three academic years 2010/2011-2012/2013.

\section{Training of school nurses and completion of anthropometric measurements}

Following initial discussions with the local authority and school nurses about adding skinfold measurements to the NCMP weight and height measurements, it was agreed that the skinfold measurements would be collected at a separate school visit from those undertaken to collect height and weight for the NCMP. This was to allow time for matching of $\mathrm{BiB}$ children to school reception class lists that for many schools are not completed and submitted to the local authority until the spring term. All of the skinfold measurements were conducted within 4 months of the NCMP height and weight measures (mean time since NCMP height and weight was 13.1 weeks (SD 7.5)). School nurses/health support workers (for ease of reading hereafter referred to as 'school nurses') in Bradford have all been trained in completing height and weight measurements for the NCMP by the Child Growth Foundation and receive yearly measurement training updates. Height was measured using the Leicester Height Measure (Seca Ltd, Leicester, UK) and weight using Seca digital scales (Seca Ltd, Leicester, UK). All height and weight measurements were recorded to one decimal place (ie, to the nearest $\mathrm{mm}$ for height and the nearest $0.1 \mathrm{~kg}$ for weight).

Experienced trained research staff from the BiB study trained the school nurses in how to measure triceps and subscapular skinfolds in children. Training was provided at regular intervals and the school nurses were provided with a written protocol (the same as that used previously for $\mathrm{BiB}$ measurements) for measuring skinfolds. Periodic monitoring and updating of training by the $\mathrm{BiB}$ researchers continued throughout the school year during which the nurses were collecting these data. Skinfold measurements were collected using Holtain Tanner/Whitehouse Calipers (Holtain Ltd) on the left side of the body. Children were seated and removed their left arm only from clothing.

\section{Assessment of feasibility and reliability of skinfold measurement}

We assessed feasibility by recording the number and percentage of children who had parental consent, child assent and valid measurements of each skinfold measurement and compared these with the number and percentage of children with NCMP height and weight measurements. These comparisons were made for the whole study sample (for school year 2012/2013) and also stratified by (1) ethnicity (defined as white British; other white; Pakistani; other South Asian; other ethnicity) and (2) gender. Feasibility would be supported by having similar proportions of children with valid skinfold measurements to the proportion with height and weight measurements.

The 2458 children in this study attended 135 Bradford primary schools. Height and weight measures for the NCMP were collected by 20 school nurses and 7 of these also collected the BiB skinfold measurements reported here. We assessed interobserver reliability in a subgroup of 84 children (12 children for each of the 7 school nurses) in whom the measurements were repeated by a trained assessor (JW) who was blind to the initial measurement.

\section{STATISTICAL ANALYSES}

All analyses were performed using STATA/SE software (Stata/SE V.12 for Windows, StataCorp LP, College Station, Texas, USA). The proportion (expressed as a percentage) of children with skinfold measurements was compared with the proportion of those with NCMP height and weight measurements stratified by ethnicity and by gender.

To assess reliability, we used the absolute technical error of measurement (TEM), the relative TEM and the coefficient of reliability $(\mathrm{R})$. These three methods assess different aspects of reliability such that the TEM provides an indication of how repeat measurements vary from the mean, the relative TEM provides a measure of size of error (variation from the mean) in relation to the magnitude of the mean and $\mathrm{R}$ provides the proportion of variation between measurements. The WHO suggest that where an expert assessor is available, acceptable TEM cut-offs should be based on the expert's intraobserver TEM where TEM values for other observers in the study should then lie within \pm 2 times the expert's TEM. Where an expert is not available, the average of well-trained observers can be used to set acceptable limits ${ }^{24}$ (shown in the final column of table 2). We took the latter approach here (using inter-reliability TEM), since among the nurses there was no individual who could be considered more experienced than the others and intrareliability repeat measurements were not taken in this study and were therefore not available for the trained assessor (JW). In addition, we used Bland-Altman plots to examine agreement between the measurers and trained researcher to identify any systematic bias, for example, differences being greater or smaller depending on the overall mean of the two measurements.

Unadjusted means of height, weight, BMI, subscapular and triceps skinfold thickness are presented by ethnic group in the original scales of each measurement $(\mathrm{m}$, $\mathrm{kg}, \mathrm{kg} / \mathrm{m}^{2}$ and $\mathrm{mm}$, respectively, for height, weight, BMI and skinfolds). These allow differences in meaningful units to be observed. To explore whether any ethnic differences had different magnitudes between the different 
anthropometric measurements, we also generated age and sex internally standardised z-scores for each measurement and regressed these z-scores on ethnicity.

\section{RESULTS}

\section{Feasibility}

Of the $2458 \mathrm{BiB}$ children in reception classes for the academic year 2012/2013 who were successfully linked to their school, $91 \%$ had a subscapular skinfold measurement and $92 \%$ had a triceps skinfold measurement taken. Height and weight were recorded at separate visits as part of the NCMP and were available for $91 \%$ and $93 \%$ of the children in this sample, respectively (table 1). There were no notable ethnic or sex differences in the proportions completing the four measurements.

\section{Reliability}

Results of interobserver reliability assessments are presented in table 2. The TEM values were all within \pm 2 times the average for all assessors. Relative TEM values ranged from $2.24 \%$ to $6.19 \%$ for triceps measurements and from $3.88 \%$ to $10.57 \%$ for subscapular measurements. R was generally over $90 \%$ for all measurers other than measurer 2 (triceps skinfold result $88.7 \%$; subscapular skinfold result $87.5 \%$ ) and one measurer 6 (subscapular skinfold result $81.6 \%$ ). Bland-Altman plots (see online supplementary figures S1-S14) showed that all mean differences were close to zero and were spread evenly across either side of the line suggesting no systematic bias.

\section{Ethnic variations in height, weight, BMI and skinfolds}

Differences in height, weight, BMI, subscapular and triceps skinfold thickness between ethnic groups and mean differences for each ethnic group relative to white British children are presented in table 3. Children classified as having other white ethnicity had similar measurements to white British children but weighed slightly more and had lower triceps skinfold thickness. Pakistani children were slightly taller but weighed less and had lower triceps skinfold thickness than white British children. A similar pattern was seen for children of other South Asian origin. Those of other ethnicity and those where ethnicity information was missing, had similar height and subscapular skinfold thickness but weighed less and had lower triceps skinfold thickness than white British children. There were no marked differences in age or gender between ethnic groups.

Figure 1 shows mean z-score differences in height, weight, BMI, triceps and subscapular skinfold for Pakistani children relative to white British children (the 2 largest groups in this sample). Compared with white British children, the Pakistani children were taller, but weighed less with the magnitudes of these differences being similar to each other. This resulted in notably lower BMI in Pakistani, compared with white British children of -0.27 SDs $(95 \%$ CI -0.37 to -0.17$)$. Triceps skinfold was also markedly lower in Pakistani compared with white British children, but subscapular skinfolds, while not statistically significant, appeared similar in both groups (mean difference $0.1 \mathrm{~mm}, 95 \%$ CI 0.1 to $0.4 \mathrm{~mm}$ ). When we further adjusted for BMI (data not presented), triceps skinfolds were $0.20 \mathrm{SD}$ lower in Pakistani compared with white British children $(95 \%$ CI 0.25 to -0.16 ) and subscapular skinfolds were $0.10 \mathrm{SD}$ higher (95\% CI 0.06 to 0.14 ).

\section{DISCUSSION}

Evidence increasingly suggests that South Asians have a characteristic phenotype of proportionately greater adiposity, increased insulin resistance and an increased risk of cardiometabolic disease compared with white Europeans. ${ }^{9}{ }^{25}$ Using data from the $\mathrm{BiB}$ cohort (as used here), we have previously shown that similar ethnic differences appear to be present at birth. ${ }^{12}$ Specifically, we showed that, despite being born smaller and lighter, for a given birth weight Pakistani infants had similar triceps and subscapular skinfold thickness measurements to white British infants suggesting greater relative fatness; they also had higher cord leptin levels even without taking birth weight into account. ${ }^{12}{ }^{14}$ In light of this,

Table 1 Number (\%) of children with height, weight and skinfold thickness measurements by ethnic group and gender

\begin{tabular}{|c|c|c|c|c|}
\hline & Height & Weight & Triceps skinfold & Subscapular skinfold \\
\hline Whole sample $(\mathrm{N}=2458)$ & $2242(91.2)$ & 2284 (92.9) & $2270(92.4)$ & 2243 (91.3) \\
\hline \multicolumn{5}{|l|}{ Ethnic group } \\
\hline White British $(\mathrm{N}=785)$ & 731 (93.1) & 736 (93.8) & 719 (91.6) & $712(90.7)$ \\
\hline Other White $(\mathrm{N}=31)$ & 28 (90.3) & 29 (93.6) & 29 (93.6) & 29 (93.6) \\
\hline Pakistani $(\mathrm{N}=904)$ & $819(90.6)$ & $844(93.4)$ & $844(93.4)$ & $830(91.8)$ \\
\hline Other South Asian (N=97) & $92(94.9)$ & 91 (93.8) & $92(94.9)$ & $91(93.8)$ \\
\hline Other $(\mathrm{N}=114)$ & $102(89.5)$ & $103(90.4)$ & $103(90.4)$ & $102(89.5)$ \\
\hline Ethnic group missing $(\mathrm{N}=527)$ & 470 (89.2) & 481 (91.3) & $483(91.7)$ & 479 (90.9) \\
\hline \multicolumn{5}{|l|}{ Gender } \\
\hline Male $(\mathrm{N}=1185)$ & $1068(90.1)$ & $1084(91.5)$ & $1088(91.8)$ & $1074(90.6)$ \\
\hline Female $(\mathrm{N}=1273)$ & $1174(92.2)$ & $1200(94.3)$ & $1182(92.9)$ & $1169(91.8)$ \\
\hline
\end{tabular}


Table 2 Technical errors of measurement (TEM) and reliability values for inter-reliability assessments*

\begin{tabular}{|c|c|c|c|c|}
\hline Measurer & Absolute TEM (mm) & Relative TEM (\%) & R (\%) & $\begin{array}{l}\text { Average TEM } \\
\text { All assessors }(\mathrm{mm})\end{array}$ \\
\hline \multicolumn{5}{|l|}{ Measurer 1} \\
\hline Triceps & 0.34 & 3.04 & 99.3 & 0.43 \\
\hline Subscapular & 0.86 & 10.57 & 97.2 & 0.57 \\
\hline \multicolumn{5}{|l|}{ Measurer 2} \\
\hline Triceps & 0.61 & 6.19 & 88.7 & 0.43 \\
\hline Subscapular & 0.60 & 9.40 & 87.5 & 0.57 \\
\hline \multicolumn{5}{|l|}{ Measurer 3} \\
\hline Triceps & 0.53 & 5.22 & 97.6 & 0.43 \\
\hline Subscapular & 0.42 & 5.66 & 98.2 & 0.57 \\
\hline \multicolumn{5}{|l|}{ Measurer 4} \\
\hline Triceps & 0.29 & 2.47 & 99.2 & 0.43 \\
\hline Subscapular & 0.28 & 3.88 & 99.1 & 0.57 \\
\hline \multicolumn{5}{|l|}{ Measurer 5} \\
\hline Triceps & 0.28 & 2.24 & 99.4 & 0.43 \\
\hline Subscapular & 0.63 & 7.88 & 98.4 & 0.57 \\
\hline \multicolumn{5}{|l|}{ Measurer 6} \\
\hline Triceps & 0.43 & 5.45 & 95.0 & 0.43 \\
\hline Subscapular & 0.63 & 10.30 & 81.6 & 0.57 \\
\hline \multicolumn{5}{|l|}{ Measurer 7} \\
\hline Triceps & 0.64 & 5.72 & 95.3 & 0.43 \\
\hline Subscapular & 0.59 & 8.87 & 92.4 & 0.57 \\
\hline
\end{tabular}

and in the knowledge that this greater fatness may underlie the increased risk of type 2 diabetes among South Asian populations, ${ }^{26}$ our aim was to develop a programme of growth monitoring to compliment routine height and weight assessments, that would be feasible to implement by school nurses but that could

Table 3 Means (SD) for each measurement by ethnic group and unadjusted mean differences in measurements for each ethnic group relative to white British children

\begin{tabular}{|c|c|c|c|c|c|}
\hline Ethnic group & Height (m) & Weight (kg) & $\begin{array}{l}\text { Triceps skinfold } \\
(\mathrm{mm})\end{array}$ & $\begin{array}{l}\text { Subscapular } \\
\text { skinfold (mm) }\end{array}$ & BMI \\
\hline \multicolumn{6}{|c|}{ Whole sample $\mathrm{N}=2458$} \\
\hline Mean (SD) & $1.08(0.05)$ & $19.0(3.1)$ & $10.1(3.4)$ & $6.3(2.2)$ & $16.1(1.8)$ \\
\hline \multicolumn{6}{|l|}{ White British $\mathrm{N}=785$} \\
\hline Mean (SD) & $1.08(0.05)$ & $19.2(2.9)$ & $11.1(3.2)$ & $6.2(1.9)$ & $16.3(1.6)$ \\
\hline \multicolumn{6}{|l|}{ White other $\mathrm{N}=31$} \\
\hline Mean (SD) & $1.09(0.05)$ & $19.6(2.6)$ & $10.4(3.0)$ & $6.3(2.0)$ & $16.4(1.3)$ \\
\hline Mean difference* & $0.01(-0.01,0.02)$ & $0.4(-0.7,1.6)$ & $-0.8(-2.0,0.5)$ & $0.1(-0.7,0.9)$ & $0.02(-0.65,0.68)$ \\
\hline \multicolumn{6}{|l|}{ Pakistani $\mathrm{N}=904$} \\
\hline Mean (SD) & $1.09(0.05)$ & $18.9(3.3)$ & $9.4(3.5)$ & $6.3(2.4)$ & $15.9(1.9)$ \\
\hline Mean difference* & $0.01(0.00,0.01)$ & $-0.3(-0.6,0.0)$ & $-1.8(-2.1,-1.4)$ & $0.1(-0.1,0.4)$ & $-0.46(-0.64,-0.28)$ \\
\hline \multicolumn{6}{|c|}{ South Asian othert $\mathrm{N}=97$} \\
\hline Mean (SD) & $1.07(0.05)$ & $18.4(3.6)$ & $10.3(3.8)$ & $6.4(2.4)$ & $15.9(2.1)$ \\
\hline Mean difference* & $-0.01(-0.02,0.00)$ & $-0.8(-1.4,-0.1)$ & $-0.9(-1.6,-0.1)$ & $0.2(-0.3,0.7)$ & $-0.45(-0.84,-0.06)$ \\
\hline \multicolumn{6}{|c|}{ Other ethnicity $\ddagger \mathrm{N}=114$} \\
\hline Mean (SD) & $1.08(0.05)$ & $18.7(3.0)$ & $9.8(2.8)$ & $6.3(2.0)$ & $16.2(1.7)$ \\
\hline Mean difference* & $-0.01(-0.02,0.01)$ & $-0.4(-1.1,0.2)$ & $-1.4(-2.1,-0.7)$ & $0.1(-0.4,0.5)$ & $-0.19(-0.55,0.18)$ \\
\hline \multicolumn{6}{|c|}{ Ethnic group missing $\mathrm{N}=52$} \\
\hline Mean (SD) & $1.08(0.05)$ & $18.9(3.2)$ & $9.9(3.3)$ & $6.3(2.2)$ & $16.1(1.8)$ \\
\hline Mean difference* & $0.00(-0.01,0.01)$ & $-0.2(-0.6,0.1)$ & $-1.2(-1.6,-0.8)$ & $0.1(-0.2,0.4)$ & $-0.23(-0.44,-0.02)$ \\
\hline \multicolumn{6}{|c|}{$\begin{array}{l}\text { *Unadjusted mean difference }(95 \% \mathrm{Cl}) \text { relative to white British children. } \\
\text { †Indian; Bangladeshi. } \\
\text { łBlack; mixed white and black; mixed white and South Asian. } \\
\text { BMI, body mass index. }\end{array}$} \\
\hline
\end{tabular}


Figure 1 Mean z-score differences $(95 \% \mathrm{Cl})$ for Pakistani infants relative to white British infants (BMI, body mass index; SF, skinfold).
Mean z-score differences $(95 \% \mathrm{Cl}$ ) for Pakistani children relative to White British children for growth measurements

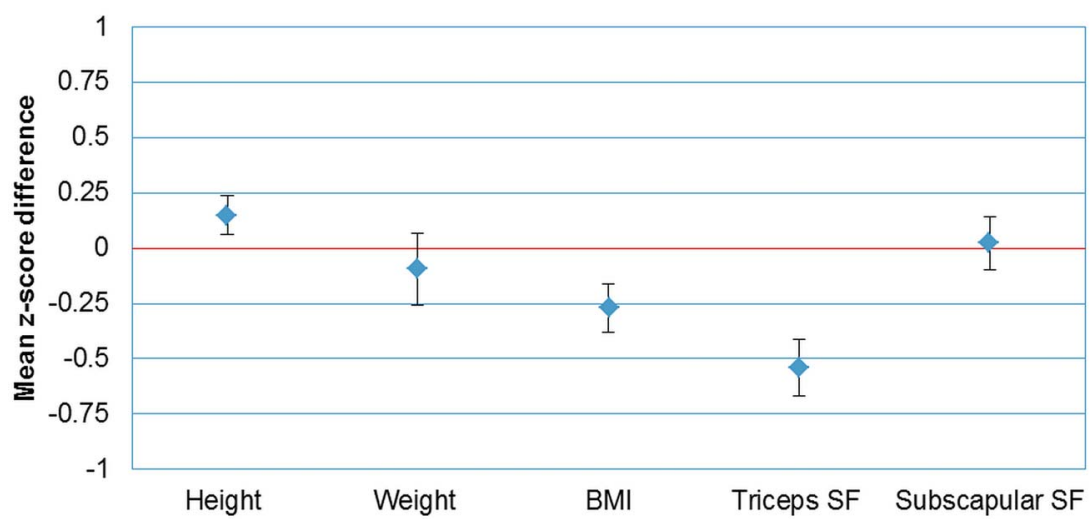

provide estimates of body fat that might better characterise ethnic differences in risk (ie, triceps and subscapular skinfold thickness). In this study, we have shown that it is feasible to implement such a programme and that similar high proportions of children having valid measurements of subscapular and triceps skinfolds, as found for weight and height measurements can be obtained. Our results show that school nurses can collect skinfold measurements with acceptable levels of reliability and with no evidence of systematic bias relative to a trained assessor.

A number of previous studies have successfully collected skinfold thickness measurements from UK children either in school using trained research staff ${ }^{10}$ or at research clinics, ${ }^{27}$ whereas here we have shown the feasibility of school nurses reliably collecting these data. As such, we have shown that it is feasible to collect these additional measurements within the existing routine programme used to assess childhood height and weight in the UK (the NCMP).

We have previously shown skinfold measurements can be reliably recorded at birth by research administrators. ${ }^{28}$ In that report, we also drew attention to the inconsistencies in the methods used and in the interpretation of results across different studies. Here, in the continued absence of any universal consensus regarding the most appropriate statistical method, ${ }^{29-32}$ we have again used three commonly reported measurements that assess different aspects of reliability. Our TEM results indicated all measurements were reliable, relative TEM was below $11 \%$ and $\mathrm{R}$ was above $90 \%$ for most measurements among most staff. These results show better reliability compared with our birth assessments particularly in terms of higher $\mathrm{R}$ and generally lower relative TEM, but as we found previously with birth measurements, the three methods did not always rank the measurers in the same order underlining the importance of using more than one approach. $^{28}$ Subscapular measurements were slightly less reliable than triceps which may be due to difficulties obtaining the measurement with only one arm removed from clothing.

In our previous publications using this cohort, we have shown that Pakistani compared with white British infants have markedly lower birth weight. They also had thinner birth subscapular and triceps skinfold thicknesses, but the magnitudes of these differences were smaller than those seen for birth weight. Now at age 4-5 years, the Pakistani children remain lighter, but they are now taller, which together contribute to a lower BMI than white British children. However, there are now notable differences in the two skinfold thicknesses, with triceps being lower in the Pakistani children but subscapular being the same in Pakistani and white British children. As Pakistani children were lighter and had on average a lower BMI, one might expect a lower, rather than similar subscapular skinfold measurement. For consistency with existing evidence and results reported at birth in this cohort, ${ }^{12}$ we further adjusted for BMI, the difference in triceps skinfold reduced but the difference in subscapular skinfold further increased. Since triceps skinfolds are considered to represent peripheral fat and subscapular centrally distributed fat, these preliminary findings suggest that the Pakistani children have begun to develop markedly more centrally distributed adiposity than white British children. As Pakistani children also had lower BMI, our results highlight that relying solely on BMI in routine surveys of childhood growth and wellbeing might incorrectly suggest some populations (here Pakistani) are healthier than others (white British) when the opposite might be true. Our findings, based here on school nurse assessments, are consistent with previous studies of UK schoolchildren assessed under researcher conditions, including the Child Health and Heart Study in England (CHASE) which found higher levels of adiposity based on skinfold and bioimpedance assessments, among South Asian children aged 911 years but that BMI underestimated the magnitude of the higher adiposity in South Asian children at this age. ${ }^{9}$

Ethnic differences in adiposity and its distribution have been reported consistently in adults and are now being identified in infants and children. ${ }^{9} 1216$ On the basis of these findings it could be suggested that lower BMI thresholds are used to indicate overweight and obesity in South Asian children, but this has been widely debated in relation to South Asian adults ${ }^{33}$ and there remains no 
clear threshold at which BMI results in adverse health outcomes. ${ }^{20} 3536$ Importantly, BMI cannot determine adiposity distribution. While waist circumference, waist:hip ratio or waist:height ratio have all been proposed to identify centrally distributed adiposity and identify those at risk, evidence from children and adults suggests a very strong correlation with BMI and similar magnitudes of association with cardiometabolic risk for these measurements as that seen with BMI. ${ }^{9}{ }^{37-39}$ Further, many children might be reluctant to uncover to the extent required for a waist measurement.

To our knowledge, this is the first UK study to undertake a city-wide programme of child skinfold measures that can compliment routine height and weight measurements to estimate fatness in reception age children. School nurse teams successfully achieved coverage similar to that reported for the $\mathrm{NCMP}^{4}$ height and weight measurements.

A limitation of our study was that we were unable to link $33 \%$ of $\mathrm{BiB}$ children to their primary school. This was mostly due to delays in schools submitting reception year pupil information to the local authority and in a minority of cases resulted from children attending schools outside the Bradford local authority area. Since completing this work we have worked with the nurses, schools and parents and are now preparing to add measurements of blood pressure, bioimpedance and the distribution of accelerometers to assess physical activity, as well as continuing to measure skinfold thicknesses in school children at and beyond reception year. Initial attempts at linking for school years after reception suggest that for those we will achieve linkage of at least $85 \%$ of $\mathrm{BiB}$ children. Importantly, there were no marked differences by ethnicity in either linkage or completion of the skinfold measurements.

To minimise discomfort and potential distress to the children, which might occur with multiple repeated measurements, we only performed inter-rater assessments. School nurse teams received comprehensive training, all staff were monitored by a trained assessor before undertaking any school visits, ongoing monitoring and training continued throughout the measurement period and all equipment was recalibrated at the start of the academic year. We therefore believe the potential for intraobserver error was minimal. Lastly, we were unable to include other South Asians (Indian and Bangladeshi) as separate groups in our analyses due to relatively small numbers of these populations in the city of Bradford. Our results may not be generalisable to other South Asian groups, though the similarity of our findings to those of $\mathrm{CHASE}^{9}$ suggests they are likely to.

\section{CONCLUSION}

Using early results from the $\mathrm{BiB}$ cohort, we have shown it is feasible for school nurses in their role as public health practitioners, to collect skinfold measurements in a similar way to the height and weight measurements collected from reception year children for the NCMP, and that these measurements are reliable. We believe these additional measurements could provide important information to examine population-level risk in populations with large proportions of South Asian children. We acknowledge that further research is required to determine whether these additional measurements do better identify risk of cardiometabolic risk in comparison to BMI and that the cost-effectiveness of these measurements is supportive of their more widespread use.

\section{Author affiliations}

${ }^{1}$ Bradford Institute for Health Research, Bradford Royal Infirmary, Bradford, UK

${ }^{2}$ School of Social and Community Medicine, University of Bristol, Bristol, UK

${ }^{3}$ Leeds Institute of Clinical Trials Research, University of Leeds, Leeds, UK

${ }^{4}$ Department of Public Health, Bradford District Metropolitan Council,

Bradford, UK

${ }^{5}$ Population Health Research Institute, St George's, University of London, London, UK

${ }^{6}$ School of Sport, Exercise and Health Sciences, Loughborough University, Loughborough, UK

${ }^{7}$ MRC Integrative Epidemiology Unit, University of Bristol, Bristol, UK

Acknowledgements Born in Bradford is only possible because of the enthusiasm and commitment of the children and parents in Born in Bradford. The authors are grateful to all participants, health professionals and researchers who have made Born in Bradford happen. They are particularly grateful to all the school nurse teams in Bradford for their support and enthusiasm for this study.

Contributors JW, DAL and JWr conceived the study idea, designed the study, obtained funds, developed the methods, were involved in managing the data collection and wrote the initial drafts of the paper. GS and JW developed the analysis plan and undertook the main analysis with supervision from DAL. $\mathrm{LL}$ and $\mathrm{KO}$ managed the data collection. JC and GS were involved in data management. PW, NC and SB developed the study aim and all authors contributed to the final draft of this paper. JW acts as the guarantor.

Funding $\mathrm{BiB}$ receives core infrastructure funding from the Wellcome Trust (WT101597MA). JW is funded by a UK Medical Research Council (MRC) Population Health Scientist Postdoctoral Award (MR/K021656/1). DAL works in a unit that receives UK MRC funding (MC_UU_12013/5) and is an NIHR senior investigator (NF-SI-0611-10196).

Competing interests None declared.

Ethics approval Bradford National Health Service Research Ethics Committee.

Provenance and peer review Not commissioned; externally peer reviewed.

Data sharing statement Scientists are encouraged and able to use BiB data. Data requests are made to the $\mathrm{BiB}$ executive using the form available from the study website: http://www.borninbradford.nhs.uk (please click on 'Science and Research' to access the form). Guidance for researchers and collaborators, the study protocol and the data collection schedule are all available via the website. All requests are carefully considered and accepted where possible.

Declaration of transparency JW affirms that the manuscript is an honest, accurate and transparent account of the study being reported; that no important aspects of the study have been omitted; and that any discrepancies from the study as planned (and, if relevant, registered) have been explained. This is an Open Access article distributed in accordance with the Creative Commons. Attribution Non-Commercial (CC BY-NC 3.0) license, which permits others to distribute, remix, adapt, build on this work non-commercially, and license their derivative works on different terms, provided the original work is properly cited and the use is non-commercial. See: http://creativecommons.org/licenses/by-nc/3.0/ 
Open Access This is an Open Access article distributed in accordance with the terms of the Creative Commons Attribution (CC BY 4.0) license, which permits others to distribute, remix, adapt and build upon this work, for commercial use, provided the original work is properly cited. See: http:// creativecommons.org/licenses/by/4.0/

\section{REFERENCES}

1. Howe LD, Chaturvedi N, Lawlor DA, et al. Rapid increases in infant adiposity and overweight/obesity in childhood are associated with higher central and brachial blood pressure in early adulthood. $J$ Hypertens 2014;32:1789-96.

2. Global status report on noncommunicable diseases 2010. Geneva: World Health Organization, 2011. http://www.who.int/nmh/ publications/ncd report2010/en/ (accessed 25 Feb 2015).

3. van Jaarsveld $\mathrm{CH}$; Gulliford MC. Childhood obesity trends from primary care electronic health records in England between 1994 and 2013: population-based cohort study. Arch Dis Child 2015;100:214-19.

4. Health and Social Care Information Centre 2015; National Child Measurement Programme: England, 2012/2013 School Year. http:// www.hscic.gov.uk/catalogue/PUB13115/nati-chil-meas-progeng-2012-2013-rep.pdf (accessed 25 Feb 2015).

5. Ogden CL, Carroll MD, Kit BK, et al. Prevalence of childhood and adult obesity in the United States, 2011-2012. JAMA 2014;311:806-14.

6. Baker JL, Olsen LW, Sørensen TI. Childhood body-mass index and the risk of coronary heart disease in adulthood. $N$ Engl J Med 2007;357:2329-37.

7. Bjørge T, Engeland A, Tverdal A, et al. Body mass index in adolescence in relation to cause-specific mortality: a follow-up of 230,000 Norwegian adolescents. Am J Epidemiol 2008;168:30-7.

8. Owen CG, Whincup PH, Orfei L, et al. Is body mass index before middle age related to coronary heart disease risk in later life? Evidence from observational studies. Int J Obes (Lond) 2009;33:866-77.

9. Nightingale CM, Rudnicka AR, Owen CG, et al. Patterns of body size and adiposity among UK children of South Asian, black AfricanCaribbean and white European origin: Child Heart And health Study in England (CHASE Study). Int J Epidemiol 2011;40:33-44.

10. Nightingale CM, Rudnicka AR, Owen CG, et al. Are ethnic and gender specific equations needed to derive fat free mass from bioelectrical impedance in children of South Asian, black African-Caribbean and white European origin? Results of the Assessment of Body Composition in Children Study. PLoS ONE 2013;8:e76426.

11. Nightingale CM, Rudnicka AR, Owen CG, et al. Influence of adiposity on insulin resistance and glycaemia markers among U.K Children of South Asian, black African-Caribbean, and white European origin: child heart and health study in England. Diabetes Care 2013;36:1712-19.

12. West J, Lawlor DA, Fairley L, et al. UK born Pakistani origin infants are relatively more adipose than white British infants: findings from 8704 mother-offspring pairs in the Born in Bradford prospective birth cohort. J Epidemiol Community Health 2013;67:544-51.

13. West J, Wright J, Fairley L, et al. Do ethnic differences in cord blood leptin levels differ by birthweight category? Findings from the Born in Bradford cohort study. Int J Epidemiol 2014;43:249-54.

14. Lawlor DA, West J, Fairley L, et al. Pregnancy glycaemia and cord-blood insulin and leptin in Pakistani and white British mother-offspring pairs: findings from a prospective pregnancy cohort. Diabetologia 2014;57:2492-500.

15. Yajnik CS, Lubree HG, Rege SS, et al. Adiposity and hyperinsulinemia in Indians are present at birth. J Clin Endocrinol Metab 2002;87:5575-80.

16. Yajnik CS, Fall CH, Coyaji KJ, et al. Neonatal anthropometry: the thin-fat Indian baby. The Pune Maternal Nutrition Study. Int $J$ Obesity 2003;27:173-80

17. Krishnaveni GV, Hill JC, Veena SR, et al. Truncal adiposity is present at birth and in early childhood in South Indian children. Indian Paediatr 2005;42:527-38.
18. Bansal N, Omolola OO, Gemmell I, et al. Effects of early growth on blood pressure of infants of British European and South Asian origin at one year of age: the Manchester children's growth and vascular health study. J Hypertens 2008;26:412-18.

19. Park $Y$, Wang S, Kitahara $C M$, et al. Body mass index and risk of death in Asian Americans. Am J Public Health 2014;104:520-5.

20. Bryant M, Santorelli G, Lawlor DA, et al. A comparison of South Asian specific and established BMI thresholds for determining obesity prevalence in pregnancy and predicting pregnancy complications: findings from the Born in Bradford cohort. Int $J$ Obes (Lond) 2014;38:444-50.

21. Boeke CE, Oken E, Kleinman KP, et al. Correlations among adiposity measures in school aged children. BMC Pediatrics 2013;13:99.

22. Gulliford MC, Mahabir D, Rocke B, et al. Overweight, obesity and skinfold thickness of children of African or Indian decent in Trinidad and Tobago. Int J Epidemiol 2001;30:989-98.

23. Wright J, Small N, Rayner P, et al. Born in Bradford Scientific Collaborators Group (2012). Cohort profile: the Born in Bradford multi-ethnic family cohort study. Int J Epidemiol 2013;42: 978-91.

24. WHO Multicentre Growth Reference Study Group. Reliability of anthropometric measurements in the WHO Multi-centre Growth Reference Study. Acta Paediatr 2006;450:38-46.

25. McKeigue PM, Shah B, Marmot MG. Relation of central obesity and insulin resistance with high diabetes prevalence and cardiovascular risk in South Asians. Lancet 1991;337:382-6.

26. Eastwood SV, Tillin T, Dehbi HM, et al. Ethnic differences in associations between fat deposition and incident diabetes and underlying mechanisms: the SABRE Study. Obesity (Silver Spring) 2015;23:699-706.

27. Ong KK, Ahmed ML, Emmett PM, et al. Association between postnatal catch-up growth and obesity in childhood: prospective cohort study. BMJ 2000;320:967-71.

28. West J, Manchester B, Wright J, et al. Reliability of routine clinical measurements of neonatal circumferences and research measurements of neonatal skinfold thicknesses: findings from the Born in Bradford study. Paediatr Perinat Epidemiol 2011;25:164-71.

29. Ulijaszek SJ, Kerr DA. Anthropometric measurement error and the assessment of nutritional status. Br J Nutr 1999;82:165-77.

30. Chumlea WC, Guo S, Kuczmarski RJ, et al. Reliability for anthropometric measurements in the Hispanic Health and Nutrition Examination Survey (HHANES 1982-1984). Am J Clin Nutr 1990;51:902S-7S.

31. Johnson TS, Engstrom JL. State of the science in measurement of infant size at birth. Newborn Infant Nurs Rev 2002;2:150-8.

32. Cameron N. The measurement of human growth. London: Croon Helm LTD, 1984.

33. Misra A. Revisions of cutoffs of body mass index to define overweight and obesity are needed for the Asian-ethnic groups. Int J Obes Relat Metab Disord 2003;27:1294-6.

34. Stevens J. Ethnic-specific revisions of body mass index cutoffs to define overweight and obesity in Asians are not warranted. Int J Obes Relat Metab Disord 2003;27:1297-9.

35. Whitlock G, Lewington S, Sherliker $\mathrm{P}$, et al, Prospective Studies Collaboration. Body-mass index and cause-specific mortality in 900 000 adults: collaborative analyses of 57 prospective studies. Lancet 2009;373:1083-96.

36. Pierce BL, Kalra T, Argos M, et al. A prospective study of body mass index and mortality in Bangladesh. Int $\mathrm{J}$ Epidemiol 2010;39:1037-45.

37. Lawlor DA, Benfield L, Logue J, et al. The association of general and central adiposity, and change in these in childhood with cardiovascular risk factors in adolescence: a prospective cohort study. BMJ 2010;341:c6224.

38. Graves L, Garnett SP, Cowell CT, et al. Waist-to-height ratio and cardiometabolic risk factors in adolescence: findings from a prospective birth cohort. Pediatr Obes 2014;9:327-38.

39. Wormser D, Kaptoge S, Di Angelantoinio E, et al. Separate and combined associations of BMI and abdominal adiposity with cardiovascular disease: collaborative analysis of 58 prospective studies. Lancet 2011;28:23-30. 